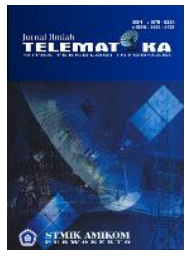

Terbit online pada laman web jurnal :

http:/lejournal.amikompurwokerto.ac.id/index.php/telematikal

Telematika

\title{
Pengelompokan Data Puskesmas Banyuwangi Dalam Pemberian Imunisasi Menggunakan Metode K-Means Clustering
}

\author{
Ahmad Chusyairi ${ }^{1}$, Pelsri Ramadar Noor Saputra ${ }^{2}$ \\ 1,2Teknik Informatika \\ Sekolah Tinggi Ilmu Komputer PGRI Banyuwangi \\ Email : niir08@gmail.com ${ }^{1}$, ramayana.x@ gmail.com ${ }^{2}$
}

\section{N F O A R T I K E L}

Sejarah artikel:

Menerima 1 Januari 2019

Revisi 21 Januari 2019

Diterima 12 Januari 2019

Online 29 Februari 2019

\section{Kata kunci:}

K-Means Clustering

Imunisasi

Puskesmas

\section{Keywords:}

$K$-Means Clustering

Health Care Center

Immunisation
Korespondensi:

Telepon: +6281329321429

E-mail: niir08@gmail.com

\begin{abstract}
ABSTRAK
Peningkatan pelayanan dan penyuluhan layanan imunisasi untuk ibu, bayi dan balita di Puskesmas dalam mencapai target cakupan Imunisasi Dasar Lengkap (IDL). Kabupaten Banyuwangi memiliki 45 Puskesmas yang akan dikelompokkan menjadi 3 kategori, yaitu: Puskesmas mencapai target IDL dengan status cukup, Puskesmas mencapai target IDL dengan status kurang, dan Puskesmas mencapai target IDL dengan status sangat baik. Tujuan penelitian ini adalah untuk mengetahui Puskesmas dalam mencapai target cakupan IDL di Kabupaten Banyuwangi. Metode yang digunakan dalam penelitian ini adalah K-Means Clustering, dimana metode ini dapat mencari partisi yang maksimal dengan prosedur iterasi yang optimal dalam mengelompokkan data secara tepat, dan memiliki ketelitian yang akurat terhadap ukuran objek, sehingga lebih terukur dan efisien dalam pengolahan data yang besar. Kesimpulan dalam penelitian ini adalah cluster pertama memiliki 19 data puskesmas dengan target imunisasi cukup, cluster kedua memiliki 24 data puskesmas dengan target imunisasi kurang, dan cluster ketiga memiliki 2 data puskesmas dengan target imunisasi sangat baik, sehingga Dinas Kesehatan dapat memberikan tugas tambahan bagi kelompok Puskesmas yang memiliki target IDL dengan status kurang untuk mengurangi angka penyakit-penyakit yang dapat dicegah dengan imunisasi (PD3I).
\end{abstract}

\section{ABSTRACT}

Improvement of immunization services and counselling services for mothers, infants, and toddlers in health care centres in achieving the target of Complete Basic Immunization (IDL). Banyuwangi Regency has 45 Puskesmas which will be grouped into 3 categories, namely: Puskesmas achieving IDL targets with sufficient status, Puskesmas achieving IDL targets with insufficient status, and Puskesmas achieving IDL targets with very good status. The purpose of this study was to determine the health centre in achieving the target of IDL coverage in the Banyuwangi Regency. The method used in this research is K-Means Clustering. This method will seek a maximal partition with optimum iteration procedure and has the best precision of the object measurement, so it is more scalable and efficient in processing a large data. The conclusion in this study is the first cluster has 19 health care centers data with sufficient immunization targets, the second cluster has 24 health care centers data with fewer immunization targets, and the third cluster has 2 health care centers data with very good immunization targets, so the Health Office can provide additional tasks for the Puskesmas group who have IDL targets with insufficient status to reduce the number of diseases that can be prevented by immunization (PD3I).

\section{PENDAHULUAN}

Berhasil atau tidaknya pembangunan kesehatan dipengaruhi oleh beberapa faktor antara lain: ketersediaan sumber daya manusia yang sehat, terampil dan ahli dan disiapkan dalam program kesehatan dengan perencanaan terpadu yang didukung oleh data dan informasi epidemiologi yang valid, karena kesehatan merupakan kebutuhan dasar bagi manusia (Kusuma, 2015). 
Pada tingkat kota atau kabupaten, pelayanan kesehatan dilakukan oleh rumah sakit umum daerah yang dikenal dengan nama puskesmas (pusat kesehatan masyarakat), dimana tugas dari puskesmas tersebut harus melaksanakan pelayanan kesehatan terhadap masyarakat semaksimal mungkin. Di Kabupaten Banyuwangi terdapat 45 puskesmas yang terdiri dari 15 puskesmas perawatan dan 30 puskesmas non perawatan, serta 180 puskesmas pembantu yang tersebar di 24 kecamatan dan 217 kelurahan/Desa (Lailiyah, et al., 2016). Berdasarkan peraturan Bupati Banyuwangi no. 13 tahun 2011, dilaksanakan program Jaminan Pelayanan Kesehatan Masyarakat Banyuwangi (JPKMB) dalam menyetarakan pelayanan kesehatan primer di Kabupaten Banyuwangi bagi seluruh masyarakat pada puskesmas secara gratis (Kusuma, 2015). Salah satu pelayanan primer JPKMB adalah pemberian imunisasi bagi bayi dan balita serta anak hingga umur 15 tahun.

Pemberian imunisasi dilakukan dalam memberikan kekebalan terhadap bayi dan balita (Hidayah, Sihotang, \& Lestari, 2018). tujuan dari imunisasi tersebut adalah untuk menurunkan angka kematian bayi yang merupakan indikator utama dalam menentukan derajat kesehatan masyarakat di tingkat provinsi maupun nasional (Kaunang, Rompas, \& Bataha, 2016). Imunisasi telah dijalankan sejak tahun 1974 untuk penyakit-penyakit yang dapat dicegah dengan imunisasi (PD3I) antara lain: tuberculosis, difteri, pertusis, campak, polio, tetanus, serta hepatitis B (Dompas, 2014). Akan tetapi, berdasarkan laporan UNICEF terdapat 27 juta anak balita di seluruh dunia yang belum mendapatkan pelayanan imunisasi secara rutin, sehingga diperkirakan menyebabkan lebih dari dua juta kematian terjadi setiap tahun (Hidayah et al., 2018). Indonesia termasuk 1 dari 6 negara yang teridentifikasi memiliki jumlah tertinggi anak-anak yang tidak terjangkau oleh imunisasi (Dompas, 2014), (Kaunang et al., 2016).

Pada tahun 2016, cakupan Imunisasi Dasar Lengkap (IDL) di Indonesia belum mencapai target. Hanya 82.1 persen yang dapat dicapai dari target cakupan IDL sebesar 91,5 persen yang dicanangkan pemerintah (Hidayah et al., 2018). Penyebab bayi dan balita tidak mendapatkan imunisasi lengkap dikarenakan kurangnya pengetahuan ibu tentang kebutuhan, kelengkapan, dan jadwal imunisasi, serta persepsi yang salah terhadap efek samping dan kandungan imunisasi (Sari, Basuki, \& Triastuti, 2016). Terutama pada provinsi Jawa Timur yang mengalami Kejadian Luar Biasa (KLB) penyakit difteri terbanyak di dunia (Izza \& Soenarnatalina, 2015), (Swardana \& Wahyuni, 2014) pada tahun 2011 serta penyakit campak terbanyak di Indonesia pada tahun 2016 (Oktaviasari, 2018).

Maka dalam mencapai target cakupan IDL, serta mengurangi angka kematian bayi dan balita untuk PD3I, puskesmas selaku ujung tombak kesehatan masyarakat harus dapat meningkatkan pelayanan dan penyuluhan layanan imunisasi, terutama bagi ibu-ibu yang memiliki bayi dan balita. Sistem Informasi penjadwalan imunisasi kesehatan bayi dan balita berbasis SMS Gateway telah dilaksanakan dalam upaya terobosan Dinas Kesehatan Kabupaten Banyuwangi dalam mempermudah informasi jadwal imunisasi kepada kader posyandu dan orangtua bayi dan balita (Chusyairi et al., 2018).

Didalam penelitian ini, maka puskesmas-puskesmas yang terdapat di Kabupaten Banyuwangi akan dikelompokkan dalam 3 kategori, yaitu puskesmas mencapai target IDL dengan status baik, puskesmas yang mencapai target IDL dengan status cukup, serta puskesmas yang mencapai target IDL dengan status kurang. Dengan demikian, maka dinas kesehatan dapat memberikan imbauan agar puskesmas dapat melaksanakan pemberian imunisasi secara lengkap terutama bagi puskesmas dengan status kurang dan cukup. Sehingga pelayanan imunisasi dapat lebih ditingkatkan dan target IDL dapat tercapai sesuai dengan target pemerintah. 
Didalam pengelompokan/pengklasteran data puskesmas tersebut, maka dipergunakan metode KMeans Clustering dalam pembagian data puskesmas tersebut yang merupakan salah satu teknik pengelompokan dalam data mining. Metode K-Means Clustering akan melakukan pencarian partisi yang maksimal dari data dengan meminimalkan kriteria jumlah kesalahan kuadrat dengan prosedur iterasi yang optimal (Sani, 2018), dan memiliki ketelitian yang akurat terhadap ukuran objek, sehingga relatif lebih terukur dan efisien dalam pengolahan data yang besar, dan juga metode ini tidak terpengaruh oleh urutan objek (Bastian, Sujadi, \& Febrianto, 2018).

Clustering secara keilmuan adalah mengelompokkan data-data atau objek kedalam cluster/group, sehingga pada setiap cluster akan terdiri dari data yang semirip mungkin atau berbeda terhadap objek pada cluster lainnya (Nasari \& Sianturi, 2016). Beberapa penelitian dalam penerapan algoritma K-Means dalam bidang kesehatan salah satunya adalah penelitian yang melakukan analisis pada penyakit menular manusia. Penelitian yang dilakukan pada Puskesmas di Kabupaten Majalengka mengkaji metode K-Means Cluster Analysis berdasarkan set variabel 6 data penyakit menular pada manusia yang terbentuk per kecamatan antara lain: diare, ISPA, kusta, malaria, tuberkulosa, dan penyakit menular seks. Hasil yang dicapai dari penelitian ini adalah data penyakit menular sehingga petugas kesehatan dapat mempersiapkan ketersediaan obat berdasarkan kelompok penyakit menular yang dihasilkan dari penelitian ini (Bastian, Sujadi, \& Febrianto, 2018).

Penelitian pengklusteran data obat pada puskesmas dengan metode K-Means Clustering, dimana ketersediaan obat harus mencukupi dan memadai pada periode selanjutnya dalam menangani suatu penyakit berdasarkan obat-obat yang telah digunakan. Sehingga hasil dari penelitian ini adalah data obat terbagi menjadi 3 yaitu data obat dengan penggunaan kurang, penggunaan obat tinggi, dan penggunaan obat tinggi sekali. Sehingga puskesmas dapat mengajukan data obat sesuai kebutuhan dengan penggunaan data obat yang tinggi serta tinggi sekali (Taslim \& Fajrizal, 2016).

Berdasarkan beberapa penelitian yang telah dibahas diatas, maka pada penelitian ini berfokus pada pengelompokan puskesmas menggunakan algoritma K-Means Clustering terhadap data imunisasi. Dari pengelompokan data dari K Means dengan hasil yang baik, sehingga dapat ditentukan kelompok puskemas yang mencapai target IDL rendah, kelompok puskesmas yang mencapai target IDL cukup, dan kelompok puskesmas yang mencapai target IDL sangat baik, sehingga angka penyakit-penyakit yang dapat dicegah dengan imunisasi (PD3I) dapat diturunkan. Dinas kesehatan dapat memberikan tugas tambahan bagi kelompok puskesmas yang memiliki target IDL rendah dalam memberikan penyuluhan terhadap masyarakat, serta berdasarkan hasil pengelompokan puskesmas dengan mempergunakan metode $\mathrm{K}$ Means Clustering dapat menjadi rujukan bagi daerah lainnya dalam penanganan penyakit yang dapat dicegah dengan imunisasi dalam pengelompokan data puskesmas.

Data yang dipergunakan dalam penelitian ini adalah data imunisasi terhadap keseluruhan data puskesmas dari dinas kesehatan kabupaten banyuwangi pada tahun 2016 hingga 2017. Pada bagian selanjutnya dirancang sebagai berikut: Analisa teoritis untuk menjelaskan metode-metode yang dipergunakan didalam penelitian ini. Metode penelitian metode-metode yang dipergunakan serta data puskesmas dan performa analisis. hasil penelitian dan pembahasan menceritakan hasil dari penelitian dalam alur sistem yang diusulkan. Terakhir adalah kesimpulan serta saran terhadap penelitian ini. 


\section{METODE PENELITIAN}

\section{Clustering}

Clustering juga disebut klasifikasi mengacu pada partisi dataset objek ke dalam kelompok objek yang paling mirip. Objek-objek ini dapat berupa numerik, kategorikal atau keduanya (Simhachalam \& Ganesan, 2014). Kemampuan algoritma clustering adalah untuk mengungkapkan struktur yang mendasari data dapat dieksploitasi dalam berbagai macam aplikasi, termasuk klasifikasi, taksonomi numerik, pemrosesan gambar, pengenalan pola, kedokteran, ekonomi, ekologi, kecerdasan buatan, penambangan data, pemodelan dan identifikasi. Berbeda dengan klasifikasi, dimana pada clustering tidak terdapat variabel target, dan mencari ke segmen data seluruh set menjadi sub kelompok yang relatif homogen (Taslim \& Fajrizal, 2016).

\section{K-Means Clustering}

K-Means merupakan salah satu dari beberapa metode data clustering non hirarki dengan sistem kerja mempartisi data yang ada ke dalam bentuk satu atau lebih cluster/kelompok. Pembagian data ke dalam cluster/kelompok pada metode ini menggunakan data dengan karakteristik yang sama yang dikelompokkan ke dalam satu cluster yang sama (Purnamaningsih, Saptono, \& Aziz, 2014).

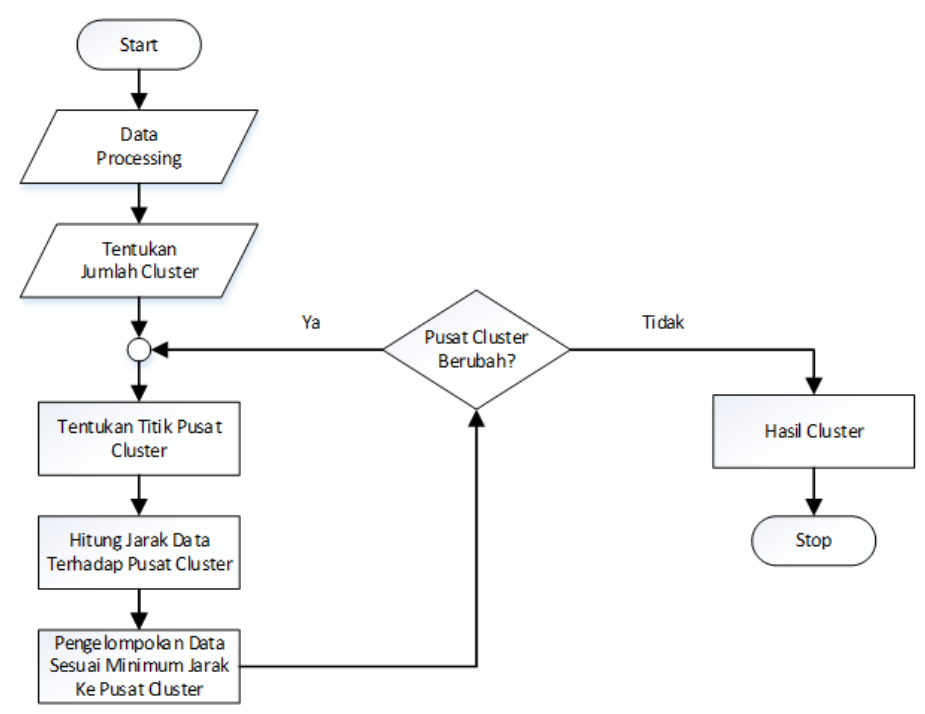

Gambar 1. Flowchart algoritma K-Means Clustering

Langkah-langkah yang dipergunakan dalam metode K-Means sesuai gambar flowchart yang ditampilkan pada gambar 1 adalah sebagai berikut (Sani, 2018):

a. Tentukan jumlah cluster yang akan dipergunakan dalam pembagian data.

b. Bangkitkan centroid awal yang diperoleh secara acak serta jumlah centroid sebanyak cluster yang akan dibuat. Pengertian centroid sendiri adalah titik pusat cluster atau awal pusat cluster.

c. Lakukan perhitungan jarak pada setiap inputan data terhadap pusat cluster hingga ditemukan jarak paling dekat dari setiap data terhadap centroid. Perhitungan jarak dilakukan dengan menggunakan persamaan Eucledian Distance (Purnamaningsih et al., 2014): 


$$
d\left(x_{i}, \mu_{i}\right)=\sqrt{\left(x_{i}, \mu_{i}\right)^{2}}
$$

d. Kelompokkan setiap data terhadap jarak pada titik pusat centroid terdekat.

e. Ubah nilai centroid yang diperoleh dari rata-rata cluster yang bersangkutan dengan persamaan:

$$
C_{k}=\frac{1}{n_{k}} \sum d_{i}
$$

Dimana:

$\mathrm{n}_{\mathrm{k}}=$ Jumlah data dalam cluster

$\mathrm{d}_{\mathrm{i}}=$ Jumlah dari nilai jarak yang masuk dalam masing-masing cluster

f. Jika anggota tiap cluster tidak ada yang berubah, maka iterasi selesai dan nilai rata-rata pusat cluster $\left(\mu_{\mathrm{j}}\right)$ akan digunakan sebagai parameter dalam penentuan pembagian data.

g. Jika tidak, maka iterasi akan dilakukan dengan menggunakan langkah b hingga langkah e.

\section{Min-Max Normalization}

Min-Max Normalization merupakan teknik ssederhana dimana pada teknik ini secara khusus dapat menyesuaikan data dalam batas yang ditentukan sebelumnya dengan batas yang ditentukan sebelumnya (Patro \& Sahu, 2015). Rumus min-max ditunjukkan pada persamaan berikut ini (Mustaffa \& Yusof, 2011):

$$
X_{n}=\frac{X_{0}-X_{\min }}{X_{\max }-X_{\min }}(3)
$$

Teknik ini akan menghasilkan data dalam rentang nilai antara 0 hingga 1 . Untuk skala nilainilai dalam rentang yang akan diingikan, maka dilakukan persamaan sebagai berikut:

$$
X_{n}=\frac{\left(X_{0}-X_{\min }\right)(\text { Maxvalue }- \text { Minvalue })}{\left(X_{\max }-X_{\min }\right)+\text { Minvalue }}
$$

Teknik ini akan dipergunakan dalam penormalisasian data imunisasi puskesmas berdasarkan keseluruhan data sehingga akan memudahkan dalam perhitungan menggunakan metode K-Means Clustering.

\section{Data Imunisasi Puskesmas}

Data pasien imunisasi bayi, balita, dan anak didapatkan dari dinas kesehatan Kabupaten Banyuwangi dari tahun 2016 hingga 2017 sebagai data uji coba pada penelitian ini. Data pasien imunisasi ditunjukkan pada tabel 1.

Terdapat 45 data puskesmas yang tersebar di kabupaten Banyuwangi. Berdasarkan data tersebut, digunakan normalisasi data terhadap data penderita diare pada tabel 1, sehingga memudahkan didalam perhitungan menggunakan K-Means Clustering.

Data yang terdapat pada setiap tahunnya pada tiap puskesmas terbagi menjadi 3 bagian antara lain data imunisasi bayi, data imunisasi balita, serta data imunisasi anak hingga umur 15 tahun. Data-data tersebut yang dipergunakan dalam pengelompokan puskesmas dalam pelayanan imunisasi terhadap bayi, balita, serta anak dibawah 15 tahun. 
Tabel 1. Data imunisasi bayi, balita, dan anak

\begin{tabular}{|c|c|c|c|c|c|c|c|}
\hline \multirow{2}{*}{ No } & \multirow{2}{*}{ Puskesmas } & \multicolumn{3}{|c|}{ Tahun 2016} & \multicolumn{3}{|c|}{ Tahun 2017} \\
\hline & & $X 1$ & $X 2$ & X3 & $X 1$ & $X 2$ & X3 \\
\hline 1 & PKM WONGSOREJO & 635 & 638 & 644 & 628 & 636 & 637 \\
\hline 2 & PKM BAJULMATI & 577 & 580 & 585 & 570 & 577 & 580 \\
\hline 3 & PKM KELIR & 307 & 308 & 312 & 305 & 308 & 310 \\
\hline 4 & PKM KLATAK & 1,017 & 1,021 & 1,032 & 1,011 & 1,026 & 1,030 \\
\hline 5 & PKM MOJOPANGGUNG & 461 & 462 & 467 & 454 & 459 & 461 \\
\hline 6 & PKM PASPAN & 544 & 547 & 553 & 536 & 544 & 544 \\
\hline 7 & PKM LICIN & 447 & 448 & 452 & 440 & 446 & 447 \\
\hline 8 & PKM SOBO & 718 & 721 & 728 & 706 & 714 & 715 \\
\hline 9 & PKM SINGOTRUNAN & 579 & 581 & 588 & 569 & 577 & 578 \\
\hline 10 & PKM KERTOSARI & 386 & 388 & 394 & 380 & 385 & 385 \\
\hline 11 & PKM KABAT & 449 & 451 & 456 & 910 & 920 & 922 \\
\hline 12 & PKM BADEAN & 386 & 388 & 390 & 786 & 796 & 797 \\
\hline 13 & PKM GITIK & 263 & 264 & 267 & 523 & 531 & 532 \\
\hline 14 & PKM GLADAG & 145 & 146 & 147 & 291 & 295 & 296 \\
\hline 15 & PKM SINGOJURUH & 705 & 708 & 714 & 691 & 704 & 707 \\
\hline 16 & PKM SONGGON & 780 & 783 & 794 & 766 & 777 & 780 \\
\hline 17 & PKM KEBAMAN & 422 & 424 & 428 & 415 & 420 & 420 \\
\hline 18 & PKM PARIJATAH KULON & 451 & 453 & 459 & 443 & 451 & 451 \\
\hline 19 & PKM WONOSOBO & 508 & 510 & 516 & 499 & 506 & 507 \\
\hline 20 & PKM KEDUNGREJO & 601 & 603 & 610 & 591 & 599 & 601 \\
\hline 21 & PKM SUMBERBERAS & 468 & 470 & 475 & 461 & 467 & 469 \\
\hline 22 & PKM TAPANREJO & 337 & 339 & 341 & 331 & 336 & 337 \\
\hline 23 & PKM TEMBOKREJO & 664 & 666 & 674 & 653 & 663 & 663 \\
\hline 24 & PKM TEGALDLIMO & 554 & 556 & 563 & 543 & 552 & 552 \\
\hline 25 & PKM KEDUNGWUNGU & 410 & 412 & 415 & 403 & 410 & 409 \\
\hline 26 & PKM PURWOHARJO & 541 & 544 & 549 & 532 & 538 & 538 \\
\hline 27 & PKM GRAJAGAN & 477 & 479 & 483 & 469 & 474 & 476 \\
\hline 28 & PKM BENCULUK & 689 & 692 & 699 & 677 & 686 & 690 \\
\hline 29 & PKM TAMPO & 417 & 419 & 423 & 410 & 416 & 418 \\
\hline 30 & PKM JAJAG & 450 & 451 & 456 & 443 & 448 & 451 \\
\hline 31 & PKM YOSOMULYO & 479 & 481 & 487 & 472 & 479 & 479 \\
\hline 32 & PKM TEGALSARI & 733 & 736 & 744 & 723 & 736 & 735 \\
\hline 33 & PKM GENTENG KULON & 731 & 734 & 741 & 718 & 728 & 731 \\
\hline 34 & PKM KEMBIRITAN & 589 & 592 & 599 & 580 & 588 & 590 \\
\hline 35 & PKM SEMPU & 496 & 498 & 502 & 487 & 493 & 496 \\
\hline 36 & PKM KARANGSARI & 490 & 491 & 496 & 481 & 487 & 490 \\
\hline 37 & PKM GENDOH & 135 & 136 & 137 & 132 & 134 & 135 \\
\hline 38 & PKM SEPANJANG & 609 & 612 & 618 & 600 & 607 & 610 \\
\hline 39 & PKM TULUNGREJO & 489 & 491 & 496 & 480 & 487 & 491 \\
\hline 40 & PKM KALIBARU KULON & 983 & 987 & 997 & 968 & 981 & 985 \\
\hline 41 & PKM KEBONDALEM & 482 & 484 & 490 & 474 & 479 & 481 \\
\hline 42 & PKM SAMBIREJO & 454 & 455 & 459 & 448 & 451 & 452 \\
\hline 43 & PKM PESANGGARAN & 327 & 328 & 332 & 322 & 326 & 328 \\
\hline 44 & PKM SUMBERAGUNG & 439 & 441 & 446 & 432 & 438 & 441 \\
\hline 45 & PKM SILIRAGUNG & 700 & 702 & 713 & 687 & 696 & 699 \\
\hline
\end{tabular}

\section{Performa Analisis}

Sistem blok diagram digunakan dalam mengetahui input data yang dibutuhkan, proses yang terjadi, hasil proses, serta interaksi yang terjadi antara pengguna terhadap sistem yang dijelaskan di dalam diagram yang dihasilkan dari hasil interaksi pada gambar 2. Dalam penelitian ini, pengklasteran data diperoleh dengan mempergunakan data input dari 45 data puskesmas selama tahun 2016 dan tahun 2017 yang telah ditampilkan pada tabel 1.

Seluruh data selanjutnya dilakukan pre-processing data menggunakan metode Min-Max Normalization sehingga memudahkan dalam penghitungan mempergunakan metode K-Means Clustering. Dari input data yang digunakan berdasarkan data dengan metode cluster sehingga pengelompokan data akan dihasilkan. 


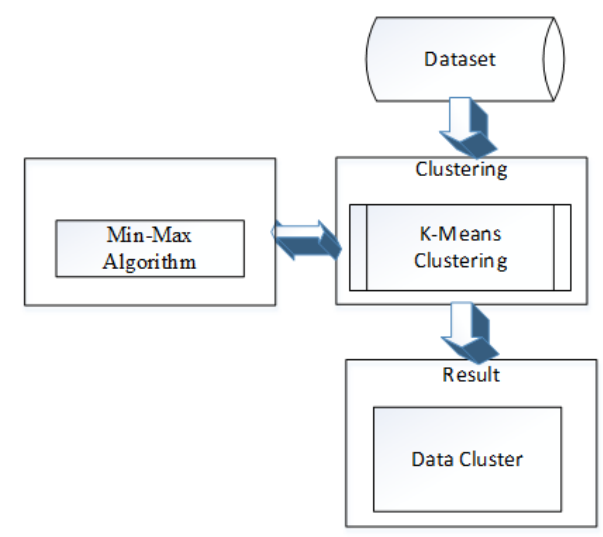

Gambar 2. K-Means Clustering model

\section{HASIL DAN PEMBAHASAN}

Normalisasi data dilakukan berdasarkan data yang ditunjukkan pada tabel 1. Penormalisasian data dilakukan dengan menggunakan metode Min-Max dimana akan dicari nilai terkecil dan terbesar berdasarkan seluruh data yang digunakan, dan dilakukan proses perhitungan pada setiap data dengan rentang nilai antara 1 hingga 100, sehingga memudahkan dalam proses perhitungan selanjutnya.

Data akan dibagi menjadi 3 cluster dan selanjutnya dilakukan pembangkitan sejumlah centroid awal secara acak berdasarkan pembagian data cluster. Kemudian dilakukan perhitungan jarak antara tiap data terhadap ketiga pusat cluster dengan menghitung derajat keanggotaan terhadap data imunisasi dengan penggunaan persamaan Euclidean Distance.

Dari perhitungan jarak tersebut, maka akan dihasilkan data-data imunisasi dengan jarak yang terdekat terhadap titik dari ketiga pusat centroid tersebut. Data tersebut akan digabungkan dalam kelompok cluster sesuai jarak terdekatnya. Dilakukan perhitungan nilai rasio berdasarkan jarak antar pusat cluster yang selanjutnya nilai ini akan dijadikan sebagai patokan dalam iterasi selanjutnya. Kemudian pada iterasi selanjutnya, dilakukan perhitungan kembali dengan mengubah nilai centroid yang diperoleh dari rata-rata cluster yang telah didapatkan.

Nilai rasio dari perhitungan yang telah dilakukan akan dibandingkan terhadap nilai rasio pada iterasi selanjutnya. Dilakukan pengecekan terhadap nilai kedua rasio tersebut apakah selisih nilai rasio berada dibawah nilai rasio pada iterasi sebelumnya. Jika nilai rasio masih besar dibandingkan nilai rasio sebelumnya, maka iterasi akan dilanjutkan dengan melakukan proses perubahan nilai centroid dan penghitungan keanggotaan data kembali. Perhitungan/iterasi akan berhenti apabila nilai rasio yang dihasilkan lebih kecil dibandingkan dengan hasil nilai rasio pada iterasi sebelumnya. Data hasil dari perhitungan menggunakan K-Means Clustering ditunjukkan pada tabel 2, 3, dan 4.

Tabel 2. Data Cluster Ketiga

\begin{tabular}{ll}
\hline No & \multicolumn{1}{c}{ Puskesmas } \\
\hline 1 & PKM KLATAK \\
2 & PKM KALIBARU KULON \\
\hline
\end{tabular}


Tabel 3. Data Cluster Kedua

\begin{tabular}{ll}
\hline No & \multicolumn{1}{c}{ Puskesmas } \\
\hline 1 & PKM KELIR \\
2 & PKM MOJOPANGGUNG \\
3 & PKM LICIN \\
4 & PKM KERTOSARI \\
5 & PKM GITIK \\
6 & PKM GLADAG \\
7 & PKM KEBAMAN \\
8 & PKM PARIJAAH KULON \\
9 & PKM WONOSOBO \\
10 & PKM SUMBERBERAS \\
11 & PKM TAPANREJO \\
12 & PKM KEDUNGWUNGU \\
13 & PKM GRAJAGAN \\
14 & PKM TAMPO \\
15 & PKM JAJAG \\
16 & PKM YOSOMULYO \\
17 & PKM SEMPU \\
18 & PKM KARANGSARI \\
19 & PKM GENDOH \\
20 & PKM TULUNGREJO \\
21 & PKM KEBONDALEM \\
22 & PKM SAMBIREJO \\
23 & PKM PESANGGARAN \\
24 & PKM SUMBERAGUNG \\
\hline
\end{tabular}

Tabel 4. Data Cluster Pertama

\begin{tabular}{ll}
\hline No & \multicolumn{1}{c}{ Puskesmas } \\
\hline 1 & PKM WONGSOREJO \\
2 & PKM BAJULMATI \\
3 & PKM PASPAN \\
4 & PKM SOBO \\
5 & PKM SINGOTRUNAN \\
6 & PKM KABAT \\
7 & PKM BADEAN \\
8 & PKM SINGOJURUH \\
9 & PKM SONGGON \\
10 & PKM KEDUNGREJO \\
11 & PKM TEMBOKREJO \\
12 & PKM TEGALDLIMO \\
13 & PKM PURWOHARJO \\
14 & PKM BENCULUK \\
15 & PKM TEGALSARI \\
16 & PKM GENTENG KULON \\
17 & PKM KEMBIRITAN \\
18 & PKM SEPANJANG \\
19 & PKM SILIRAGUNG \\
\hline
\end{tabular}

Hasil grafik dari pembagian data dengan menggunakan metode K-Means Clustering terhadap data puskesmas dalam pemberian imunisasi ditunjukkan pada gambar 3 dibawah ini.

Pada data cluster yang pertama menghasilkan kelompok puskesmas sebanyak 19 data antara lain puskesmas Wongsorejo, Bajulmati, Paspan, Sobo, Singotrunan, Kabat, Badean, Singojuruh, Songgon, Kedungrejo, Tembokrejo, Tegaldlimo, Purwoharjo, Benculuk, Tegalsari, Genteng Kulon, Kembiritan, Sepanjang, dan Siliragung. Pada data cluster kedua menghasilkan kelompok puskesmas sebanyak 24 data antara lain puskesmas Kelir, Mojopanggung, Licin, Kertosari, Gitik, Gladag, Kebaman, Parijatah Kulon, Wonosobo, Sumberberas, Tapanrejo, Kedungwungu, Grajagan, Tampo, Jajag, Yosomulyo, Sempu, Karangsari, Gendoh, Tulungrejo, Kebondalem, Sambirejo, Pesanggaran, dan Sumberagung. Dan data cluster ketiga hanya memiliki 2 data puskesmas yaitu puskesmas Klatak dan Kalibaru Kulon. 


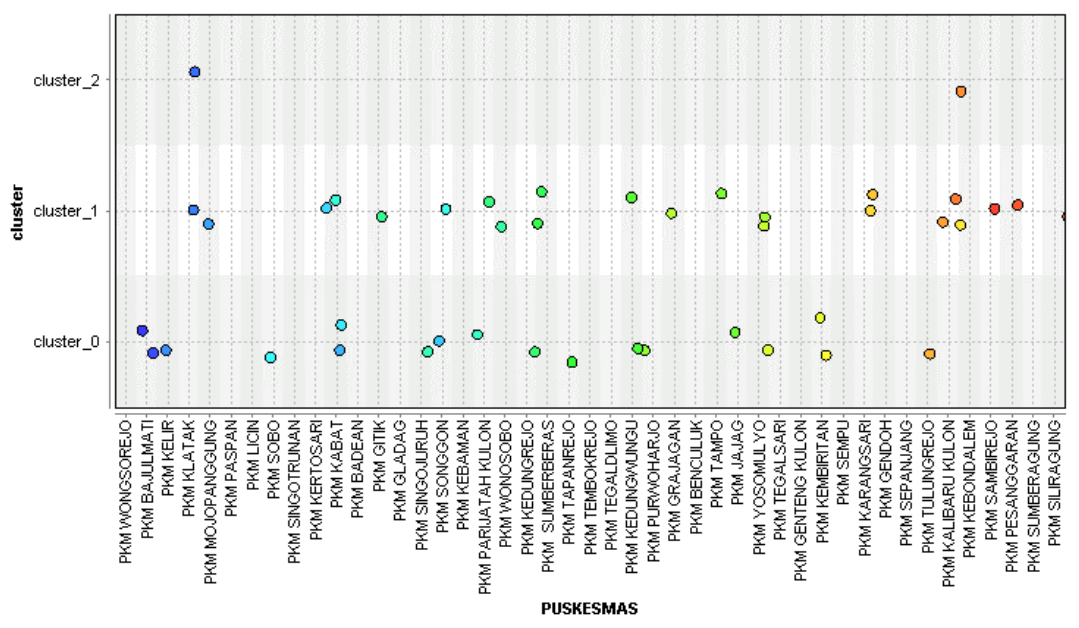

Gambar 3. Grafik data clustering puskesmas

\section{KESIMPULAN DAN SARAN}

Berdasarkan hasil yang telah diperoleh dari pengelompokan data puskesmas dalam pemberian imunisasi terhadap bayi, balita, dan anak hingga usia 15 tahun, maka dihasilkan 3 kluster dengan jumlah data puskesmas yang berbeda. Data pada cluster pertama mewakili data puskesmas dengan target imunisasi cukup, data pada cluster kedua dengan target imunisasi kurang, serta data pada cluster ketiga dengan target imunisasi sangat baik. Sehingga, dengan data yang telah dihasilkan dapat dijadikan acuan bagi dinas kesehatan Kabupaten Banyuwangi dalam memberikan pemberitahuan bagi puskesmaspuskesmas dalam memberikan peningkatan penyuluhan dan pelayanan imunisasi terhadap bayi, balita, dan anak hingga usia 15 tahum terutama bagi puskesmas yang memiliki target imunisasi kurang serta kurang sehingga target IDL dapat dicapai pada periode selanjutnya resiko kematian anak, bayi, dan balita dapat diturunkan.

Dari penelitian yang telah dilakukan, diharapkan dalam penambahan metode optimalisasi sehingga hasil yang didapatkan semakin optimal dan lebih baik lagi dalam pengklasteran data puskesmas berdasarkan data yang ada.

\section{UCAPAN TERIMA KASIH}

Terima kasih kepada Kementerian Riset, Teknologi dan Pendidikan Tinggi (Ristek Dikti) Direktorat Jenderal Penguatan Riset dan Pengembangan yang telah memberikan bantuan secara finansial kepada penulis untuk publikasi paper penelitian melalui pendanaan Penelitian Dosen Pemula (PDP) berdasarkan Surat Keputusan nomor T/140/E3/RA.00/2019 dan Perjanjian/Kontrak nomor 194/KET./F.1/STIKOM PGRI/III/2019.

\section{DAFTAR PUSTAKA}

Bastian, A., Sujadi, H., \& Febrianto, G. (2018). Penerapan Algoritma K-Means Clustering Analysis Pada Penyakit Menular Manusia (Studi Kasus Kabupaten Majalengka). Jurnal Sistem Informasi (Journal of Information System), 14(1), 26-32.

Chusyairi, A., Kurnia Hadi Muktining Nur, T., Haryanto, D., PGRI Banyuwangi, S., Banyuwangi, B., Kesehatan Banyuwangi Jl Jend Yani No, D. A., \& Jawa Timur, B. (2018). Sistem Informasi 
Jadwal Imunisasi Kesehatan Bayi Dan Balita Berbasis Sms Gateway. Jurnal Teknologi Informasi, 13(1), 38-43.

Dompas, R. (2014). Gambaran Pemberian Imunisasi Dasar Pada Bayi Usia 0-12 Bulan. Jurnal Ilmiah Bidan (Jidan), 2(2), 71-76.

Hidayah, N., Sihotang, H. M., \& Lestari, W. (2018). Faktor Yang Berhubungan Dengan Pemberian Imunisasi Dasar Lengkap Pada Bayi Tahun 2017. Jurnal Endurance, 3(1), 153-161.

Izza, N., \& Soenarnatalina. (2015). Analisis Data Spasial Penyakit Difteri di Provinsi Jawa Timur Tahun 2010. Buletin Penelitian Sistem Kesehatan, 18(2), 211-219.

Kaunang, M. C., Rompas, S., \& Bataha, Y. (2016). Hubungan Pemberian Imunisasi Dasar Dengan Tumbuh Kembang Pada Bayi (0-1 Tahun) Di Puskesmas Kembes Kecamatan Tombulu Kabupaten Minahasa. Ejournal Keperawatan (E-Kp), 4(1), 1-8.

Kusuma, B. M. A. (2015). Implementasi Program Jaminan Pelayanan Kesehatan Masyarakat Banyuwangi (JPKMB) Dalam Mewujudkan Pelayanan Kesehatan Primer Bagi Seluruh Lapisan Masyarakat. IJPA-The Indonesian Journal of Public Administration, 2(1), 103-117.

Lailiyah, S., Prayoga, D., Haksama, S., \& Mandagi, A. M. (2016). Analisis Pengembangan Simpus "Si Jempol Sehat Wangi” Di Kabupaten Banyuwangi. Jurnal IKESMA, 12(1), 8-17.

Mustaffa, Z., \& Yusof, Y. (2011). A Comparison of Normalization Techniques in Predicting Dengue Outbreak. In International Conference on Business and Economics Research (Vol. 1, pp. 345349). Malaysia.

Nasari, F., \& Sianturi, C. J. M. (2016). Penerapan Algoritma K-Means Clustering Untuk Pengelompokkan Penyebaran Diare Di Kabupaten Langkat. Cogito Smart Journal, 2(2), 108119.

Oktaviasari, K. E. (2018). Hubungan Imunisasi Campak Dengan Kejadian Campak Di Provinsi Jawa Timur. Jurnal Berkala Epidemiologi, 6(2), 166-173. https://doi.org/10.20473/jbe.v6i22018.166173

Patro, S. G. K., \& Sahu, K. K. (2015). Normalization: A Preprocessing Stage. arXiv Preprint arXiv: 1503.06462 .

Purnamaningsih, C., Saptono, R., \& Aziz, A. (2014). Pemanfaatan Metode K-Means Clustering dalam Penentuan Penjurusan Siswa SMA. Jurnal ITSmart, 3(1), 27-33.

Sani, A. (2018). Penerapan Metode K-Means Clustering Pada Perusahaan. Jurnal Teknologika, 8(1).

Sari, D. N. I., Basuki, S. W., \& Triastuti, N. J. (2016). Hubungan Pengetahuan Ibu Tentang Imunisasi Dasar Dengan Kelengkapan Imunisasi Dasar Bayi Di Wilayah Kerja Puskesmas Bendo Kabupaten Magetan. Biomedika, 8(2), 6-12.

Simhachalam, B., \& Ganesan, G. (2014). Possibilistic Fuzzy C-Means Clustering On Medical Diagnostic Systems. In International Conference on Contemporary Computing and Informatics (IC3I) (pp. 1125-1129).

Swardana, N. F., \& Wahyuni, C. U. (2014). Faktor Yang Mempengaruhi Ibu Terhadap Ketidakikutsertaan Batita Pada Sub Pin Difteri. Jurnal Berkala Epidemiologi, 2(2), 227-239.

Taslim, \& Fajrizal. (2016). Penerapan Algorithma K-Mean Untuk Clustering Data Obat Pada Puskesmas Rumbai. Jurnal Teknologi Informasi \& Komunikasi Digital Zone, 7(2), 108-114. 